\title{
Üzerine Televizyon Düşmesi Sonucu Meydana Gelen Çocuk Ölümlerinin Retrospektif Değerlendirilmesi
}

\author{
Ertuğrul GÖK ${ }^{1}$, Recep FEDAKAR ${ }^{2}$, Süleyman SiVRí ${ }^{3}$
}

1 Dicle Üniversitesi Tıp Fakültesi, Adli Tıp Anabilim Dalı, Diyarbakır.

2 Bursa Uludağ Üniversitesi Tıp Fakültesi, Adli Tıp Anabilim Dalı, Bursa.

3 Kahramanmaraş Sütçü İmam Üniversitesi Tıp Fakültesi, Adli Tıp Anabilim Dalı, Kahramanmaraş.

\section{ÖZET}

Televizyon düşmesi, çocuklarda sıklıkla künt kafa travmasına bağlı önemli morbidite ve mortalite nedenidir. Televizyon düşmesi nedeniyle ölen olguların detaylı incelenmesi alınacak tedbirler için yol gösterici olacaktır. Bu çalışmada Adli Tıp Kurumu Diyarbakır Grup Başkanlığı tarafından 2005-2014 yılları arasında Diyarbakır'da ölü muayeneleri veya otopsileri yapılmış olan 9174 olgunun ölü muayene veya otopsi raporları incelendi. İncelenen olgulardan üzerine televizyon düşmesi nedeniyle ölmüş olduğu kesin olan çocuk yaş grubundaki 24 olgu çalışmaya alındı. Olguların tamamının $(\mathrm{n}=24)$ künt kafa travmasına bağlı öldükleri, hepsinin yaş grubunun 1-4 yaş aralığında olduğu, olguların $13(\% 54,2)$ tanesinin kız cinsiyette olduğu ve en çok olguya yaz mevsiminde $(\% 45,8)$ rastlandığı saptandı. Televizyon düșmesine bağ 1 ölümlerin tamamının kaza kaynaklı önlenebilir halk sağlığı sorunu olduğu saptandı.

Anahtar Kelimeler: Kaza. Çocuk ölümü. Adli olgu. Kafa travmass. Televizyon düşmesi.

Retrospective Assessment of Child Deaths as a result of Falling Television

\begin{abstract}
Television falling is an important cause of morbidity and mortality in children, often due to blunt head trauma. Detailed analysis of the cases who died due to falling televisions will be a guide for the prevention protocols. In this study, postmortem examinations or autopsy reports of 9174 cases which were carried out by the Council of Forensic Medicine, Diyarbakir Group Chairmanship between 2005 and 2014 were examined. Of the examined cases, 24 cases in the pediatric age group whose cause of death was television falling were included in the study. It was found that all of the cases $(n=24)$ died due to blunt head trauma, all of them were between the ages of 1 and $4,13(54.2 \%)$ of the cases were female, and most cases (45.8\%) were observed in the summer season. It was determined that all deaths due to falling TVs are preventable public health problems caused by accident.
\end{abstract}

Key Words: Accident. Child death. Forensic case. Head trauma. Falling TV.

Çocukluk döneminde kazalara bağlı olarak yaralanma ve ölüm riski yüksektir. Çocukların fiziki olarak küçük olmaları, tecrübe ve koordinasyon eksiklikleri, motor sistemlerinin yeterince gelişmediğinden dolayı ani reaksiyon güçleri zayıf olması nedeniyle erişkinler için hayatı tehdit etmeyen durumlar çocuklar için

Geliş Tarihi: 09.Nisan.2021

Kabul Tarihi: 16. Haziran.2021

Dr. Ertuğrul GÖK

Dicle Üniversitesi Tıp Fakültesi

Adli Tıp Anabilim Dalı, Diyarbakır

Tel.: 05545842720

E-posta: ertugrulgk@gmail.com

Yazarların ORCID ID Bilgisi:

Ertuğrul GÖK: 0000-0003-1573-283X

Recep FEDAKAR: 0000-0002-2029-9674

Süleyman SIVRİ: 0000-0003-0929-3420 hayatı tehdit edebilir ${ }^{1,2}$. Önemli bir halk sağlığı problemi olan ev kazalarına maruz kalan kitle daha çok okul öncesi çocuklardır ${ }^{3}$. Okul öncesi yaştaki çocukların kafalarının vücuda oranla daha büyük olması, kafa kemikleri henüz tam gelişmediği için beyin dokusunun kafa travmasından kolay etkilenmesi nedeniyle çocukluk çağı travmalarında kafa travmaları ciddi yaralanmalar olarak karşımıza çıkmaktadır. Özellikle televizyonun hayatımıza girdiği ve çok yaygınlaştığı son yıllarda çocukluk çağı ev kazalarında televizyon düşmesi kaynaklı kafa travmasına bağlı hasarlar sık görülmektedir ${ }^{4}$. Bu nedenle çocukluk dönemi kazaların oluş mekanizmasını, morbiditesini ve mortalitesini bilmek, özellikle önlenebilir kazaların önüne geçebilmek için koruyucu programların hazırlanmasına yardımci olacaktır.

$\mathrm{Bu}$ çalışmanın amacı ev kazalarından olan üzerine televizyon düşmesi nedeniyle öldüğü saptanan çocuk 
olguları inceleyip, literatür eşliğinde tartışarak, elde edilen veriler 1şığında ev kazalarına bağlı önlenebilir ölümler üzerinde yapılabilecek hususları vurgulamaktir.

\section{Gereç ve Yöntem}

Mevcut çalışmada Adli Tıp Kurumu Diyarbakır Grup Başkanlığı tarafindan 2005-2014 yılları arasındaki 10 y1llık periyotta adli otopsisi veya sadece adli ölü muayenesi yapılmış olan 9174 adet adli ölüm olgusunun dosyası geriye dönük olarak taranmıştır. Üzerine televizyon düşmesi sonucu ölen çocuk olgular çalışmaya dahil edilmiştir. Bu çalışmanın etik kurul izni Adli Tıp Kurumu Başkanlığı Eğitim ve Bilimsel Araştırma Komisyonu'ndan 17/09/2019 tarih ve 21589509/2019/747 sayılı yazı ile alınd1.

Çalışmaya dahil edilen olguların yaş, cinsiyet, yaralandığı mevsim, olayın olduğu yer, hastanede yatış süreleri, ölüm yerleri, ölüm nedenleri belirlendi ve istatistiksel analizleri yapıldı.

\section{Biyoistatiksel Analiz}

Olguların yaşları ortalama \pm standart sapma; dosya kayıtlarına göre televizyon düşmesi tespit edilen olgular sayı (n) ve yüzde (\%) olarak belirtilmiştir. İstatistiksel analiz için (Statistical Package for the Social Sciences) SPSS 13.0 programı kullanılmıştır.

\section{Bulgular}

2005-2014 yılları arasındaki 10 yıllık periyotta otopsi veya sadece ölü muayenesi yapılan 9174 adli olgu içerisinde 18 yaş altı 24 olgunun $(\% 0,26)$ üzerine televizyon düşmesi sonucu öldüğü belirlenmiştir. $\mathrm{Bu}$ olguların 11 'ine $(\% 45,8)$ adli otopsi yapılmış, geri kalan olgulara ise sadece adli ölü muayenesi yapılmıştır. 24 çocuk olgunun hepsinin 1-4 yaş aralığında olduğu görüldü. Olguların 13'ü $(\% 54,2) \mathrm{k1z}, 11^{\prime} \mathrm{i}$ $(\% 45,8)$ erkek cinsiyet olarak tespit edildi. Olguların 20 'si $(\% 83,3)$ hastane ortamında ölmüş, geri kalanı hastaneye ölü duhul olarak gelmiştir. Hastaneye canlı olarak gelen hastaların $(n=20), 10$ tanesinin $(\% 50)$ ilk gün içinde vefat ettiği tespit edilmiştir. Olguların tamamında (24/24) künt kafa travması bulguları olduğu saptanmıştır. Bu olguların 22'sinde (\%92) kafatası kemik kırıkları saptanmıştır. Kafatasında kırık saptanan olguların 14'ünde (\%64) sadece kafatası kaide kemiklerinde, dördünde (\%18) sadece kafatası kubbe kemiklerinde, dördünde (\%18) ise kafatasının hem kubbe hem de kaide kemiklerinde kırıklar olduğu saptanmıştır. Olguların ikisinde $(\% 8,3)$ ise, (birisi kız, birisi erkek) kafatasında kırık saptanmamıştır. Kafatası kemiklerinde kırık olmayan olgulardan üç yaşındaki k1z olguda subaraknoidal kanama (SAK), beyinde ventrikül içi kanama saptanırken; bir yaşındaki erkek olguda ise SAK ve subdural hematom saptanmıştır. Televizyon düşmesi nedeniyle incelenen olguların tamamında $(n=24)$ beyinde SAK tespit edilmiştir. Kafatasında sadece kaide kemiği kırığı olan olgular $(\mathrm{n}=14)$ incelendiğinde; kemik kırıklarına ilave olarak üçünde $(\% 21,4)$ beyin dokusunda kontüzyon, birisinde $(\% 7,1)$ epidural hematom, birisinde $(\% 7,1)$ subdural hematom, birisinde $(\% 7,1)$ oksipital loblarda harabiyet ve birisinde $(\% 7,1)$ akciğerlerde kontüzyon saptanmıştır. Kafatasında sadece kubbe kemiği kırığı olan olgular $(n=4)$ incelendiğinde; kemik kırıklarına ilave olarak birisinde (\%25) beyin dokusunda kontüzyon ve ikisinde (\%50) ventrikül içi kanama saptanmıştır. Kafatasında kubbe ve kaide kemiklerinde birlikte kırık saptanmış olan olgular $(n=4)$ incelendiğinde ise; kemik kırıklarına ilave olarak birisinde $(\% 25)$ beyin dokusunda kontüzyon, birisinde (\%25) epidural hematom olduğu saptanmıştır.

Kazaların hepsi ev ortamında meydana gelmiş olup olguların oluş zamanı mevsimsel olarak incelendiğinde, en çok olgunun yaz aylarında meydana geldiği tespit edilmiştir (Tablo). Olgulardan alınmış olan örnekler üzerinde yapılmış olan toksikolojik analizlerde hiçbir toksik madde bulunmamıştır.

Tablo. Olguların mevsimlere göre dağılımı

\begin{tabular}{|l|c|c|}
\hline \multicolumn{1}{|c|}{ Mevsim } & Olgu Sayısı (n) & Yüzdesi (\%) \\
\hline Kış & 3 & 12,5 \\
\hline İlkbahar & 4 & 16,7 \\
\hline Yaz & 11 & 45,8 \\
\hline Sonbahar & 6 & 25 \\
\hline Toplam & $\mathbf{2 4}$ & $\mathbf{1 0 0}$ \\
\hline
\end{tabular}

\section{Tartışma ve Sonuç}

Çocukların çeşitli nedenlerden dolayı travmalara bağlı yaralanma ve ölme riski erişkinlerden daha yüksektir. Çünkü çocuklar etraftaki potansiyel risklerin farkında olmadan, yaşadığı çevreyi tanımak için devamlı bir araştırma halindedirler. Künt kafa travmaları çocukluk döneminde yaralanma ve ölümlere neden olan durumlardandır ${ }^{5}$. Künt kafa travmasına neden olarak çocuk ölümlerine yol açan televizyon düşmesi kazaları, adli ölüm olgularından olup doğal olmayan ölümlerdendir. Ceza Muhakemesi Kanunu'nun (CMK) 159. Maddesi, doğal olmayan bir ölüm meydana geldiği durumlarda, durumun Cumhuriyet Başsavcılığına bildirilmesi yükümlülüğünü getirmiş olup bu kapsama giren hallerde ölünün gömülmesini ancak Cumhuriyet savcısının yazılı iznine bağlamıştır ${ }^{6}$. Adli ölüm olgularının ihbarından sonra, Cumhuriyet Savcısı yönetiminde adli otopsi veya sadece adli ölü muayenesi yapıldıktan sonra defin ruhsatı verilmektedir ${ }^{7}$. Bizim çalışmamızdaki bütün olguların adli ölüm olguları olması nede- 


\section{Televizyon Düşmesi Sonucu Çocuk Ölümleri}

niyle hepsine adli işlemler (adli otopsi/adli ölü muayenesi) yapılmıştır.

Türkiye İstatistik Kurumu verilerine göre; ülkemizde dışsal yaralanma ve zehirlenme nedenli ölümler, ölüm nedenleri arasında 6. sırada gelmektedir. Çocukluk çağı ile ilgili ölümler incelendiğinde beş yaş altı ölüm oranlarının yıllar geçtikçe azaldığ Çalışmamızda televizyon düşmesi sonucu ölen çocukların hepsi 1-4 yaş arasında idi. Literatürde çocukluk çağı kazaları incelendiğinde en yüksek oranın bizim çalışmamıza benzer şekilde 1-4 yaş arası çocuklarda olduğu görülmektedir ${ }^{9-11}$. Mevcut çalışmanın verileri incelendiğinde kız cinsiyetin üzerine televizyon düşmesi nedenli ölüm oranı erkek cinsiyete göre daha fazla bulunmuştur. Bilimsel literatür incelendiğinde çocukluk çağı travmalarının cinsiyetle bağlantısı konusunda farklı sonuçlar mevcuttur. Pakiş ve ark., çocukluk çağı travmalarının \%77.8'inin erkek cinsiyette meydana geldiğini göstermiştir ${ }^{9}$. Korkmaz ve ark., ise çocuk acil servisine travma nedeniyle başvuran olgularının \%50'sinden fazlasının erkek hastalar olduğunu bildirmiştir $^{12}$. Bununla birlikte üzerine televizyon düşmesi sonucu ölen çocukları içeren bir çalıșmada, olguların \%70'ini kız çocuklar oluşturmaktayd ${ }^{13}$.

Adli tıbbi değerlendirmede kafatasında tam kat kemik kırıkları, epidural kanama, subdural kanama, SAK, ventrikül içi kanama, kafa içi yumuşak doku kontüzyonları gibi patolojilerin varlığı, yaşamı tehlikeye sokan yaralanmalardandır ${ }^{13,14}$. Çalışmadaki çocuklarda kafatası kemik kırıkları saptanmasının nedeni olarak çocuklar ayakta iken üzerine televizyon düşmesi sonucu yaralanmalarına bağlamaktayız. Olguların iki tanesinde kafatası kemiği kırı̆̆ı olmamasına rağmen SAK olmasını çocukların kafa kemiklerinin esnek olmasından dolayı kırık olmadan beyin kanamasına sebep olmasına bağlamaktayız. Olguların çoğunun hastane öncesinde veya hastanedeki ilk günde ölmelerinin sebebinin ise ciddi travma maruziyetinden kaynaklandığını düşünmekteyiz.

Çalışmadaki kazalar mevsimsel olarak incelendiğinde en çok olgunun yaz mevsiminde gerçekleştiği görülmektedir (Tablo). Literatürdeki çalışmalarda da bizim sonuçlarımıza benzer şekilde çocukluk çağı kazalarının yaz mevsiminde daha fazla olduğu görülmekte$\operatorname{dir}^{12-15}$. Bunun sebebi olarak, çocukların yaz mevsiminde hava şartlarından dolayı daha hareketli olmasından kaynaklandığını düşünmekteyiz.

Sonuç olarak üzerine televizyon düşmesi nedenli ölümler, önlenebilir çocuk ölümlerindendir. Toplumun temelini oluşturan çocukların sağlığının korunması öncelikle ev ortamını onlar için güvenli hale getirmekle olacaktır. Ev ortamının çocuklar için uygun hale getirilmesi, gerekli tedbirlerin alınması, ev kazalarından korunma yolları hususunda ailelerin eğitilmesi ile bu ölümlerin önüne geçilebilir. Fakat alınan tüm tedbirlere rağmen ölümlü bir kaza olmuşsa CMK usüllerine uygun bir şekilde adli otopsi veya sadece adli ölü muayenesi yapılıp, ölümün nedeni ortaya konulmalıdır.
Etik Kurul Onay Bilgisi:

Onaylayan Kurul: Adli Tıp Kurumu Başkanlığı Eğitim ve Bilimsel Araștırma Komisyonu

Onay Tarihi: 17.09 .2019

Karar No: 21589509/2019/747

Araștırmacı Katkı Beyanı:

Fikir ve tasarım; E.G, R.F.,S.S.; Veri toplama ve ișleme E.G. Analiz ve verilerin yorumlanması R.F., E.G, S.S.; Makalenin önemli bölümlerinin yazılması R.F., S.S., E.G.

Çıkar Çatışması Beyanı

Makale yazarının çıkar çatışması beyanı yoktur.

\section{Kaynaklar}

1. Byard RW. Accidental Childhood Death and the Role of the Pathologist. Pediatr Dev Pathol.2000;3:405-418.

2. Korkmaz T, Zerrin E, Kahramansoy N. Acil Servise Gelen Pediatrik Adli Olguların Değerlendirmesi: Retrospektif bir çalışma. Haseki Tıp Bülteni.2014;52:271-277.

3. Schmertmann M, Williamson A, Black D. Stable Age Pattern Supports Role of Development in Unintentional Childhood Poisoning. Inj Prev. 2008;14:30-33.

4. Turan Y, Uysal C, Korkmaz M ve ark. Kaza ile Üzerine Cisim Düşmesine Bağlı Hastaneye Başvuran Hastaların Değerlendirilmesi. Dicle Tip Dergisi.2015;42:51-54.

5. Savku E, Huban A, Yalcındağ FN. Çocukluk Çağında Televizyon Düşmesi Sonucu Görülen Göz Problemleri. Turk J Ophthalmol.2013;43:451-454.

6. 5271 say1lı Ceza Muhakemesi Kanunu (2004). T.C. Resmi Gazete, Kabul Tarihi: 17/12/2004. Erişim adresi: https://www.mevzuat.gov.tr/MevzuatMetin/1.5.5271.pdf, Erişim tarihi:12/03/2021.

7. Gök E, Hakeri H. Adli Vakalarda Tibben ve Hukuken Otopsi mi Organ Nakli mi Önceliklidir? Sözlü Bildiri. IV. Uluslararası Tıp Hukuku Kongresi (Online). 8-10 Ocak 2021.

8. Türkiye İstatistik Kurumu. Ölüm ve Ölüm Nedeni İstatistikleri, Say1:33710, Yayım tarihi: 24/06/2020. Erișim adresi: https://data.tuik.gov.tr/Bulten/Index?p=Olum-ve-Olum-NedeniIstatistikleri-2019-33710, Erişim tarihi:16/06/2021

9. Pakiş I, Karapirli M, Yaycı N. Üzerine Kaza İle Cisim Düşmesine Bağlı Çocuk Ölümleri. Acıbadem Üniversitesi Sağlık Bilimleri Dergisi. 2010;2:81-84.

10. Türkoğlu A, Tokdemir M, Yaprak B, Börk T, Tunçez FT, Şen M. Üzerine Televizyon Düşmesi Sonucu Meydana Gelen Çocuk Ölümleri: Olgu Sunumu. Fırat Üniversitesi Sağlık Bilimleri Tıp Dergisi. 2014;28:35-37.

11. Şahin S, Doğan Ş, Aksoy K. Çocukluk Çağı Kafa Travmaları. Uludağ Üniversitesi Tip Fakültesi Dergisi 28:45-51, 2002.

12. Korkmaz MF, Bostancı M, Tutanç M. Bir Üçüncü Basamak Hastanede Yatan Adli Nitelikli Çocuk Hastaların Değerlendirilmesi. J Pediatr Emerg Intensive Care Med. 2019;6:140-145.

13. Demiray Şahan Sİ, Kara ZG, Kılıç İ, Değirmenci B, Akar T, Demirel B. Televizyon Düşmesine Bağlı Çocuk Ölümleri. 15. Adli Bilimler Kongresi, sayfa 140. 12-15 Nisan 2018, Antalya.

14. Balcı Y, Çolak B, Gürpınar K, Anolay NN. (Güncelleme Editörleri). Türk Ceza Kanunu'nda Tanımlanan Yaralama Suçlarının Adli Tıp Açısından Değerlendirilmesi Rehberi. Adli Tıp Uzmanları Derneği, Adli Tıp Kurumu Başkanlığı, Adli Tip Derneği, 2019.

15. Demir U, Aşırdizer M, Etli Y, Kartal E, Gümüş O, Hekimoğlu Y. Beş Yaşın Altındaki Çocukların Kazayla Ölümlerinin Analizi. Adli Tıp Dergisi. 2017;31:17-25. 
